\title{
Sobre El pan Y EL VINO de EFRaÍN Barquero: Por una liturgia DE LA SOLIDARIDAD
}

\section{NaÍN NÓMEZ*}

\section{INTRODUCCIÓN}

$\mathrm{E}$ N OTRA parte (Antología de Efraín Barquero, Lom Ediciones, 2000), hemos abordado la manera como algunos símbolos proliferan en la producción poética de Efraín Barquero, formando una pléyade de elementos que se estructuran y desestructuran, que permanecen y mutan, dando sentido a un mundo donde lo humano y la naturaleza se concilian, se integran y se intercambian en un movimiento permanente. Entre ellos mencionamos la piedra, el fuego, el agua, la casa, la mesa, el pan, el cuchillo, la tierra y el pueblo, entre otros (5-21). Si bien, desde su primera obra, el poeta ha mostrado que su trabajo va y viene permanentemente entre los mismos signos y símbolos, como una búsqueda constante que no se agota en la evolución sino que se profundiza en el cambio, resulta indudable también que esa búsqueda se ha ido depurando en una cristalización cada vez más acentuada de ciertos ritornelos que persiguen la misma figura discursiva, la de lo humano esencial, en un entrelazamiento que permanece en lo fundamental. Es de esta manera que La piedra del pueblo inicia, en 1954, una travesía literaria que se origina en la búsqueda de una epifanía humana en medio de un mundo cada vez más desbordado por la técnica y la fragmentación, pero donde la voz poética mantiene incólume esa religazón (en el sentido de "religare") con el mundo ancestral de los antepasados, vinculados en forma espontánea al medio natural, del cual se sienten parte integral. Cada libro, cada texto posterior, ha ido acentuando ese camino que es una

* Poeta, crítico y académico de literatura chilena y latinoamericana en la Universidad de Santiago de Chile.Santiago, Chile. E-mail: nain.nomez@usach.cl 
especie de espiral concéntrica, donde seres y cosas se amplían bajo el foco de un narrador movible que cambia su perspectiva para retomar las voces del origen, que también son las de la muerte y la regeneración continua. Ya sea en La compañera (1956), el Enjambre (1959), El viento de los reinos (1967), las Epifanías (1970), El viejo y el niño (1992), las Mujeres de oscuro (1992), o La mesa de la tierra (1998), desde los títulos, los poemas aluden siempre a elementos de un solo mural totalizador, que patentiza un rico mundo personal desplegado a partir de la singularidad de un sujeto que avisora (a través del recuerdo, la memoria), un universo en vías de desaparición, pero que todavía nos dice algo fundamental sobre el hombre, su destino, sus orígenes y su temporalidad. Sin embargo, en cada nueva obra, el poema se deshuesa más, se va desmenuzando de todo lo accesorio, se va haciendo metáfora de sí mismo, hasta adquirir un carácter casi aforístico, sin dejar por ello de hablarnos desde la singularidad humana en forma obsesiva.

\section{CONSIDERACIONES GENERALES}

En El pan y el vino (Lom, 2008), su último libro publicado, todo lo dicho anteriormente se densifica hasta entregarnos una especie de colofón, una apuesta final, una síntesis de su propia escritura. Con un lenguaje cada vez más silencioso (si pudiera decirse así), el poeta escribe un libro dialogante compuesto por 27 textos con título y otros textos intercalados casi simétricamente, con una especie de voz en off de tono menor (aunque no tanto), que es una especie de interlocución o soliloquio del sujeto sobre sí mismo, sobre los otros y sobre la propia escritura anterior. Todo ello, enmarcado en cada página de una manera precisa y donde cada gesto o convención requiere de una marca necesaria que articula significantes y significados como una totalidad que se fija y que se desplaza en un vaivén permanente. En este sentido, los quiebres del verso, los vacíos del silencio en la página dados por el montaje, la ausencia de puntuación o el encabalgamiento, el 'dash' de la voz en off, los cambios pronominales y especialmente el corte suspensivo del verso final de cada texto, inducen al lector a interpretar no sólo lo que se dice, sino también el cómo se dice. Más que nunca antes, pareciera que Barquero estuviera empeñado en fijar e integrar de la manera más exacta posible la expresión oral con el texto escrito. Cada sentencia suena como si tuviera vida propia, independiente de las otras, pero al mismo tiempo formando un todo espeso y envolvente, donde sintagma y paradigma se aluden mutuamente y se enriquecen en la corriente de la sentencia y aun más allá de ella.

Como característica general, se podría decir que tanto en los textos con título como los sin título, se genera un sujeto que habla en primera persona, pero que se desplaza hacia el 'tú' o hacia el 'él' o hacia el 'nosotros' y el 'ellos' en el primer caso, mientras que en el segundo, se desdobla en una segunda 
voz que más parece un monodiálogo para hablar consigo mismo. Este sujeto es el motor del texto, aunque a veces desaparezca en las otras figuras pronominales, bajo la forma del diálogo o de la voz impersonal. El sujeto que se enuncia como 'Yo' no deja de estar presente, pero casi siempre se difumina y es difícil saber si está siendo representado bajo otras figuras a través de su continuo desplazamiento. En este sentido, 'Yo' y 'Otro' son movimientos de un sujeto que es Uno y es Todo, como si se tratara de una figura borgeana que se construye en la mente, en la sensación, en el recuerdo, desdoblada hasta el infinito, pero también unívoca.

Todos los poemas que tienen título adquieren en principio esta forma impersonal a través de la cual se universaliza la situación que se plantea, aunque de inmediato el narrador la singulariza con algún detalle que lo retrotrae a la experiencia personal, para finalmente, en una vuelta circular, volver al aserto general con que se inició y cerrar el poema con un estribillo totalizador: la espiral concéntrica de que hablaba antes. De este modo, los títulos representan esta generalización en que prima 'el' o 'la' o 'un': por ejemplo, "El comensal en que jamás reparamos", "La herramienta que hace a los hombres", "El hombre caído", "El pan con sabor a otros", etc. El 'Yo' se desplaza hacia el 'Tú' o hacia el 'El', a veces como alguien distinto que servirá para reafirmar lo mismo, a veces como un desdoblamiento del propio Yo que se experiencia como un Otro que es el Mismo y cuya condición doble no puede borrar. En este sentido, la trama de las personas/personajes son sus propios interlocutores en constante transformación y espejeo, son todos los hombres visibles e invisibles y también todos nosotros, los lectores que espejeamos el texto.

\section{YO Y EL DOBLE: LA ALIANZA ENTRE LO SINGULAR Y LO COLECTIVO}

En "El comensal en quien jamás reparamos", el 'eterno extraño', el 'doble', el 'otro', el 'comensal' es el ser invisible que somos también todos nosotros; nuestro doble es el del sueño que es nuestro ser inconsciente, pero también el colectivo humano, el todo en el que no reparamos: 'El hombre solamente se reconoce al morir' (7). Se alude aquí al vacío y a la nada que nos separa del ser íntegro que no somos, pero cuya carencia sentimos y vemos: el eterno extraño que somos nosotros mismos. En "La estrella matutina", pensamos, que el foco está centrado en la utopía, cuyo campo semántico tiene que ver también con la luz y la búsqueda de una cierta trascendencia ínsita en el sentido de la vida que se decanta en el recuerdo y la memoria. Aquí el sujeto, en primera persona, se asimila con los muertos a través del recuerdo de la estrella que da el sentido a la vida y que permite la reconciliación entre la luz y las tinieblas; la piedra de la tiniebla del origen que se une con la luz de la 
estrella de la muerte que luego cambia de órbita para volver a regenerarse. Lentamente empiezan a confluir en los textos los símbolos fundamentales de esta poesía. Uno de ellos es la casa. En "La casa a medio hacer", la vida se equipara a la casa y en ambas el papel del tiempo es central: 'recuerda su vida como un solo cuarto redondo' (13). Alejarse hacia atrás o ir hacia adelante es como perderse en los cuartos de la casa, donde el tiempo es trastocado y la edad se pierde. El tema del 'Yo', el 'Otro', el 'Extraño', reaparece en el poema "La entreabierta mano del sueño", que se refiere a la imposibilidad del amor total a través de la mano del sueño: 'por qué estamos lejos estando cerca cuando nos amamos' (15). Ella responde desde muy lejos, desde un lugar desconocido, porque el sueño es una casa donde uno habita solo y los demás son unos extraños. A diferencia del extraño que llega como comensal o invitado y que se integra a través de los alimentos esenciales, del símbolo de la mesa y el gesto de la fraternidad, aquí el sueño que nos transforma en Otros, nos separa: la mano del sueño no es la mano del que acoge, porque el sueño nos desdobla y nos convierte en Otro.

Los poemas van enlazando los mismos simbolos una y otra vez hasta conformarlos como parte de una estructura ancestral. En "El animal marcado" la relación con la naturaleza se establece a partir del sacrificio del animal, que al igual que el sacrificio humano, genera vínculos de sangre que aluden, por un lado a la libertad y por otro a la muerte como forma de renacer. En ambos casos, reaparece la idea del sacrificio del hermano, nuestro doble a quien matamos una y otra vez y al hacerlo nos matamos a nosotros mismos. Se reitera la idea de que el uno, el otro y el todo son lo mismo. Los símbolos de la semilla y la piedra reaparecen en el texto "El mundo que nos rodea". El hombre 'sentado en una piedra' se relaciona con el silencio y la muerte. El silencio es su lenguaje más allá de la vida, porque sigue viviendo en la semilla y en la piedra, que son elementos arraigados en la naturaleza. La piedra es el símbolo de la continuidad de la existencia del muerto y por eso, 'volvieron a mirar la piedra en donde estaba sentado/ Volvieron cada día a sentarse un rato en ella' (21). Así, sentarse en la piedra señala la continuidad de la vida del muerto, el diálogo con el silencio: la piedra es el puente entre la vida, la muerte y la vida de nuevo, en un proceso de constante regeneración. Es el elemento que aglutina las vidas de los vivos y los muertos: es también el sitio de la rememoración donde fluyen el recuerdo y la memoria. En el poema "Un pozo/ un árbol", la contraposición de ambos elementos que son también símbolos, ratifica el planteamiento del 'Yo' que es un 'Otro', un extraño que soy yo mismo: 'el mismo que muere en mí cuando me voy muy lejos' (23). Si el árbol representa la casa y la mesa, el ansia de vida, la trascendencia hacia el cielo; el pozo representa el olvido, las vueltas sobre sí mismo, la falta de hogar, la extrañeza, el que 'camina por dentro de sí mismo' ...'dando vueltas alrededor de un pozo sin fondo' (Ibíd). Pero ambos sujetos son siempre el mismo en diferentes momentos o bajo distintas pulsiones. Claramente el 
poeta está aludiendo a la complejidad de nuestra conciencia, contradictoria, compleja, llena de transformaciones, heracliteana en su transcurrir. En otros poemas, esta asimilación de todos los hombres se ratifica con la imagen del hijo y de la madre como en "Un vaso de agua fresca" donde todos somos hijos con sed y hambre, viajeros extraños que al ser reconocidos aceptamos también nuestra universalidad de parias y de acogidos: 'un hombre con sed y hambre' (25). El tema del hijo y del niño incide en la vertiente barqueriana de escudriñar en el eterno retorno que va del padre al hijo y viceversa, como signo y gesto de una potencial solidaridad humana.

\section{EL PAN Y EL VINO: UNA EXPERIENCIA SOLIDARIA}

En la misma línea de lo expresado anteriormente, aparecen el pan y el vino como alimentos primordiales del gesto solidario, representados en el visitante y el visitado, las figuras que más se repiten en el libro de Barquero, como sujetos emblemáticos de la libertad humana, al mismo tiempo que de su precariedad, signados ambas por unos cuantos gestos de humanidad. Visitante y visitado, como signos del encuentro humano, tienen su contrapartida en la víctima y el victimario que representan 'el sello de un hombre' (32). Reaparece aquí la figura de Cristo, de los apostoles, de Judas, del criminal y la víctima, de la sangre; aparecen el odio, el frío, la amargura, el perdón, gestos de lo humano que se repiten y que nos convierten a todos en el mismo. Víctimas y victimarios somos todos y también los que tenemos vergüenza de la traición y de verter sangre: 'todos bajamos la cabeza' (Ibíd).

La solidaridad representativa del pan que se confunde con la mano ("El pan con sabor a otros") se entroniza con su origen, con el grano y la semilla (así como la mesa y la casa también tienen su origen en el trabajo humano colectivo), cuya genealogía se cuenta en el poema "La cáscara/ el grano", uno de los textos fundamentales del libro. Allí se retoma intertextualmente la relación entre el niño que recuerda el cuarto oscuro donde se guardaba el grano con el proceso de su germinación y su transformación en alimento, articulando en la memoria el tiempo humano con la imagen del viejo mirando al niño: 'Y después al ver al niño alejarse corriendo y saltando / mirarse largamente las dos manos vacías' (40). La germinación del grano en la oscuridad como en el poema "Granero" de Enjambre, vuelve a mostrar esa búsqueda permanente del sujeto que reconstruye en la memoria el momento en que la semilla se convierte en grano, momento crucial, axis mundi que se temporaliza en algún rincón del inconsciente, pero que sólo se retrotrae en el sueño, en el poema, en la imagen del 'silencio', ahora convertido en espacio de profundidad rememorante, donde vida, muerte y resurrección se forjan como una sola imagen en el centro de la existencia: 'el cielo gota a gota/ la tierra grano a grano' (Ibíd). En el poema "la distancia entre el

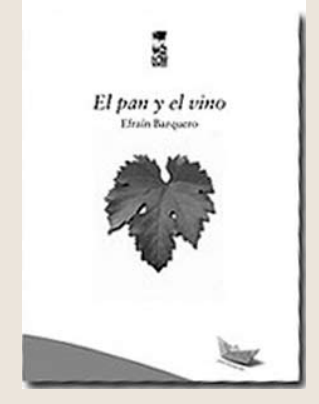

\begin{tabular}{l|l}
147 & Atenea 498 \\
\cline { 2 - 2 } & II Sem. 2008
\end{tabular} 
cielo y la tierra" (42), vuelve a aparecer 'el gran silencio de la tierra y el cielo' como el escenario de uno de esos momentos 'esenciales' que representa el encuentro con el extraño y el cruce en el camino como 'umbral' del re-conocimiento donde se condensan 'la vida' y la 'memoria': 'haciendo de todos los caminos / el único camino por donde los hombres se reconocen' (Ibíd). En el poema "El gesto que nunca se termina de hacer" (44), la idea central se refiere al 'acoger' y el 'acogerse', situación que se pluraliza. El poema retoma los temas del extraño, del visitante, del camino y de la casa, focalizándolos en el gesto de la acogida, que es simultáneamente el gesto de auto-acogerse con el sentido de liberar y de auto-liberarse. El acoger como auto-acogernos nos entrega la certeza de que alguien nos recibirá cuando llegue la muerte, nos permite visualizar nuestra vida hacia atrás pero también hacia delante. Como en otros poemas, es el gesto de salir al encuentro del otro (recibirlo, invitarlo, acogerlo), lo que nos permite recuperar nuestra relación esencial con el mundo y la naturaleza.

Como contrapartida, tenemos la casa vacía que refiere al hombre vacío y nos hace tomar conciencia del sentido del origen y por eso 'algo se removió adentro tratando de despertar' ("Un adiós imposible", 46). En ese origen está el 'nudo' (nudo del árbol materno y nudo del árbol con que se construye la casa y nudo-nudillo de la mano con que se saluda, se golpea la puerta y se despide) original que desaparece cuando alguien se despide de la casa, de si mismo, del otro ('morada y morador') que somos nosotros mismos bajo otra figura, cuando desaparecemos en la noche dejando la casa vacía: ella queda vacía de nosotros y nosotros de ella. El elemento central en este poema es la despedida: en ese gesto, mano, casa, origen, árbol, utensilios, espejo donde se es uno y se es otro, el habitar la casa y el sí mismo, desaparecen. El 'amparo de la noche' es la oscuridad de la muerte o la posibilidad de la regeneración: 'el anticipo de ese sueño que soñamos antes de nacer' (Ibíd).

La representación del mensajero que es viejo y es niño a la vez, representativo de la continuidad de la vida como un fenómeno natural que se asemeja al proceso de cambio de la semilla en grano y fruto, esos 'granos oscuros de tierra sin edad', reaparece en el poema "Es viejo el mensajero y su mensaje" (51). La imagen del río heracliteano que vislumbramos en otro poema ("El lugar/el instante") a través del paralelismo y la integración con el otro (el que es 'más que un hermano/ más que si nos hubiéramos bañado en el mismo río del origen', 49), es también aquí central. 'El mensajero / es el hombre mismo': niño, hombre y viejo, repetición de la semilla en el grano y en el fruto, repetición de la vida madurando en el granero de la naturaleza. De esta manera, la desgracia es consubstancial al mismo ser que es capaz de la solidaridad y la fraternidad o de invitar y ser invitado: 'tú recibes el golpe / que no hace sangrar/ que te hace igual a ti mismo' ("El porte de la desgracia", 53). Entre tierra y cielo, vida y muerte 'no hay nadie/ en ninguna 
parte', porque la desgracia es parte del mismo ser humano que es capaz del sacrificio y la consolación. Así como la desgracia, el sacrificio, la consolación y la solidaridad se articulan en el meollo central de lo esencial humano, como elementos constitutivos de una humanidad caída y sublimada; las identidades también se multiplican, se asumen como diferentes y unívocas, como temporalidades que se renuevan en un espacio que es simultáneo y continuo. La sobreviviencia del otro, como el extraño de sí mismo que aparece en "El otro" (60), es también el hombre que abraza al hijo del amigo como si fuera el padre, haciendo de la circularidad del abrazo, la circularidad de un tiempo que gira en redondo como un anillo, símbolo de esa amistad en el poema "El abrazo" (62). Esa circularidad creadora que refuerza la amistad se extiende permanentemente al mundo natural. El emisario-mensajero de "El porte de la desgracia" (54), 'deja de ser un desconocido/ para ser tu propio doble' y cuando se va, la confluencia original del mundo deja de tener sentido: la puerta se cierra y 'no quieres mirar el lecho ni la mesa', los lugares donde se producen los actos esenciales, porque los elementos vitales desaparecen $o$ se reducen a meras huellas de lo humano: 'migas de pan/manchas de vino/ granos de tierra caídos' (Ibíd). De este modo, los poemas vuelven a cerrarse sobre la imagen del encuentro que funde al yo consigo mismo, con el otro.

\section{EL PAN Y EL VINO COMO LITURGIA: LA VOZ EN OFF}

Lo que llamamos la voz en off adquiere el carácter de un pensamiento puesto entre paréntesis de manera minimalista, una especie de soliloquio-coloquio o monodiálogo consigo mismo, una especie de montaje del subsconciente que reflexiona sobre ciertos momentos o circunstancias que la memoria retrotrae desde el pasado, elucubra en el presente o proyecta hacia el futuro. Lo que relevan los fragmentos en off es la idea de comunión sagrada que representa la liturgia de la mesa servida con el otro presente o ausente. La idea de umbral aparece como central: el umbral de la puerta, el umbral de la conciencia, el umbral entre el otro y yo. Cruzar ese umbral es el juego del reconocimiento y del encuentro que se da en la ofrenda: la copa de vinosangre que permite también el autorreconocimiento: 'mi copa colmada de algo/que era yo mismo o mi sangre más pura' (8). Cuando no hay ofrenda, cuando se come solo, el sujeto se siente culpable porque no hay con quien compartir: 'como si el pan fermentara en tu cuerpo pidiéndote el más antiguo tributo de la tierra/ como si el vino se embriagara en ti sin transformarte' (10). El acto de comer y beber nos vuelve a religar con los otros, los antepasados y los que van a venir, los muertos y los vivos 'en el tejido invisible de los gestos humanos' (12). Incluso esto ocurre cuando se bebe solo o cuando se ha vaciado la copa, que en su interior vacío mantiene la relación humana 
que se forjó en el acto del encuentro. La copa se ilumina con el gesto 'que brilla en sus ojos' (16), porque guarda todavía el calor de ese encuentro o el recuerdo que se rememora al escanciarla.

$\mathrm{Al}$ rememorar a los otros (el ausente, el caminante) aparece el silencio de la palabra 'donde se acepta o niega todo lo que somos ahora' (18), donde solo hablan los actos en su movimiento anterior a la palabra: el calor de la mano, la cuchara que evoca la comida, los labios que se abren. Es el llamado ancestral anterior a la palabra, anterior al sí o al no que congelará nuestros actos y les impondrá un sello de verdad o falsedad. Es por ello que el acto de comer nos devuelve a ese momento anterior a todo lenguaje articulado, nos devuelve a la igualdad original 'donde todos somos iguales' (20) cuando se vuelve a repartir la semilla de la tierra. Así, el pan y el vino se convierten en los elementos de la continuidad humana a través de la relación misteriosa con cada invitado, que es siempre uno y que también es siempre distinto. El alimento es la correa transmisora de la unión de todos los que quisiste y te quisieron, de los que ya no vienen y que estuvieron en la mesa: es el umbral y el cruce entre una edad y otra: es el espacio/tiempo del pasaje-aprendizaje de una vida con otra, 'un nuevo día donde el destino de todos se cumple a la vez en cada uno' (26). La repetición litúrgica de los actos aparece como un elemento fundamental en la obra de Barquero. Esa liturgia rememora el acto sagrado como una imago mundi que se repite al infinito, en una intemporalidad que recurre a otra memoria fuera de la linealidad de la nuestra. Allí es donde el pan y el vino se muestran como los alimentos del origen y del fin, provistos de un aura casi sagrada que repercute en la vida humana. Como señala el poeta en otro texto, 'pareciera que al comer y beber siguieras aguardando la plenitud de un solo fruto en el árbol...el primer sabor en la boca de un niño/ el último recuerdo en la boca de un anciano' (33). Axis Mundi de todo llamado y de toda respuesta, la hora del pan y la hora del vino aparecen desde la mitología cristológica, como el ser mismo del hombre enfrentado al sacrificio, la solidaridad y la traición: 'siente que es él mismo un bocado/ donde el pan no se endurece/ donde el vino jamás se avinagra' (35). Pan y vino son también elementos litúrgicos para el reencuentro con la memoria que sostiene la genealogía humana, el padre, la madre y 'el calor del único fuego sin ceniza' (37). El rito se cumple una y otra vez 'en el vuelo sin fin de los días' (45): el pan y el vino consolidan el instante de la celebración, las nupcias, el regocijo del encuentro que fija el instante, a la vez que echa a andar la memoria y el recuerdo para remontarse a los orígenes y entonces 'comprendemos por un segundo lo eterno/ lo inexplicable' (48) o como se dice en otro de los textos, 'como si al mezclar el pan y el vino en sus bocas pudieran transmutar todo lo que vivieron en un solo momento' (57). 


\section{COLOFÓN INCONCLUSO}

El libro se cierra con el último texto de la voz en off. Este texto dialoga en forma totalizadora con el poema anterior titulado "El abrazo", que recoge en la imagen del 'anillo/abrazo', la línea de continuidad de la especie humana, 'el anillo que pasa de la mano del padre/ a la mano del hijo' (62). El texto en off, el último, resume el acto esencial en un paradigma humano: 'todo lo que se hizo carne y sangre en el hombre/ se sublima en el pan/ se redime en el vino' (63). Carne y sangre, pan y vino, sintetizan ahora el sentido de la vida humana: sublimar y redimir reabren la pasión cristológica, pero la enmarcan en la pasión de cada hombre, de su sobrevivencia, de su ternura y de su vacío siempre remontable a través de la liturgia ancestral de la comunión con los otros hombres (y mujeres).

El pan y el vino de Efraín Barquero, con su juego discursivo y retórico recurrente y circular, renueva el vínculo con un mundo natural que, al ser negado, parece alejarnos cada vez más de nosotros mismos. Así, el poema nos habla, como diría Heidegger, de nuestras huellas originales en el rostro de la tierra y del mundo. Así tambien, nos diría Marx, en su representación cultural/escritural, el ser humano quiere recuperar su vínculo perdido con el otro, a través del trabajo esencial y de la pertenencia de sí mismo. 